\title{
COMPOSITION AND RHEOLOGICAL PROPERTIES OF MICROALGAE SUSPENSIONS: IMPACT OF ULTRASOUND PROCESSING
}

Marta Martínez-Sanz ${ }^{\mathrm{a} *}$, Agustín Garrido-Fernández ${ }^{\mathrm{a}}$, Ana Mijlkovic ${ }^{\mathrm{b}}$, Annika Krona ${ }^{\mathrm{b}}$, Antonio Martínez-Abad ${ }^{\mathrm{a}}$, José M. Coll-Marqués ${ }^{\mathrm{c}}$, Amparo López-Rubio ${ }^{\mathrm{a}}$, Patricia LopezSanchez ${ }^{\mathrm{b}}$

${ }^{a}$ Food Safety and Preservation Department, IATA-CSIC, Avda. Agustin Escardino 7, 46980 Paterna, Valencia (Spain).

${ }^{\mathrm{b}}$ Product Design, Agrifood-Bioeconomy and Health, RISE Research Institutes of Sweden. Frans Perssons väg 6, SE-412 76, Gothenburg (Sweden).

${ }^{\mathrm{c}}$ Biotechnology Department, IATA-CSIC, Avda. Agustin Escardino 7, 46980 Paterna, Valencia (Spain).

*Corresponding author: Tel.: +34 963200022; fax: +34 963636301

E-mail address: mmartinez@,iata.csic.es 


\begin{abstract}
In this study the rheological properties of aqueous suspensions of three microalgae species, Nannochloropsis gaditana, Scenedesmus almeriensis and Spirulina platensis, were investigated as a function of solids content, and related to their composition and microstructure. In addition, the impact of ultrasound processing on their structuring ability was also studied. The less rigid character of the Spirulina platensis cell walls (with very low carbohydrate contents) and the presence of extracellular components promoted cell-cell interactions, yielding suspensions which showed a shear thinning behaviour at lower concentrations than Nannochloropsis gaditana and Scenedesmus almeriensis. It is noteworthy that the three species showed different viscoelastic properties at $25 \mathrm{wt} . \%$ total solids. Spirulina platensis suspensions showed a more elastic behaviour and lower frequency dependence, characteristic of weak gels, whilst Nannochloropsis gaditana and Scenedesmus almeriensis behaved more like viscous liquids. The ultrasound treatment did not affect the cell wall integrity, but it promoted the release of intracellular components (some of which could have been partially degraded) and disrupted physical interparticle interactions in Nannochloropsis gaditana and Scenedesmus almeriensis. This has an impact on the rheological properties, increasing the viscosity of Nannochloropsis gaditana suspensions, while the viscosity of Scenedesmus almeriensis suspensions was reduced. The outcomes of this work give insights into the exploitation of these microalgae species in soft materials for food, pharma and other technological applications.
\end{abstract}

Keywords: microalgae; suspensions; rheology; cell wall polysaccharides; ultrasounds 


\section{Introduction}

Microalgae are a renewable biomass source which in the last decades have found applications within very diverse sectors such as the production of biofuels, the food industry, pharma and cosmetics $[1,2]$. In particular, there is an increased interest in the use of microalgae in food products due to their high nutritional value, which is based on their high protein content, their interesting lipid profile and the presence of bioactive compounds such as carotenoids, phycobilins, polysaccharides, vitamins, and sterols [2, 3]. Although microalgae are mainly commercialised as dietary supplements, more and more food products containing microalgae, such as pasta, snack foods, candy bars or gums, and beverages, have been recently launched into the market [4-7]. To make better use of the nutritional benefits of microalgae, more research is needed to understand their impact in food structure and processability. For instance, it has been recently demonstrated that Spirulina platensis microalgae interfere with the gelatinization process of starch, having an impact on the properties of extruded starch foams [8, 9]. Rheological properties of microalgae suspensions are relevant for food processability and for the textural properties of food systems. The existence of microalgae species with distinct cell wall composition and microstructure brings the possibility of producing microalgae-based foods with a broad range of rheological characteristics.

The rheological properties of suspensions depend on several factors, among them the solid particle concentration described by the particle volume fraction [10]. The maximum particle volume fraction, which is the number of particles that can be packed in a certain volume, depends on the particle properties such as the size, morphology and hardness. Other factors influencing the rheology of suspensions are the particle size distribution, interparticle forces, and the viscosity of the continuous liquid phase. Whilst the mechanics of dilute and 
semi diluted suspensions are well understood, there are still many uncertainties for concentrated suspensions [11]. Experimental and theoretical studies on systems ranging from monodisperse spherical particles at high concentrations to polydisperse suspensions with different morphologies have been carried out for more than fifty years [12-14]. However, the application of such models to microalgae suspensions is challenging due their high polydispersity, particle softness, the presence of crystalline and amorphous states, and the often highly non-spherical shape of the particles. Nevertheless, there are a number of studies regarding rheological properties of microalgae suspensions in the literature showing that below a critical concentration, most microalgae suspensions display Newtonian behaviour and above a certain concentration, some microalgae suspensions exhibit nonNewtonian fluid behaviour [15-19]. Whilst the cell wall composition of many land plants is well established, the cell wall composition and structure of the hundreds of thousands of microalgae species remains widely unexplored. Microalgae species which have been investigated present distinct molecular components, intra- and intermolecular linkages, and cell wall microstructure. For instance, microalgae belonging to the Nannochloropsis gaditana species have been reported to present a bilayered cell wall composed of a cellulosic inner wall protected by an outer hydrophobic algaenan layer [20]. In contrast, the cell wall from Spirulina platensis has been seen to present a structure of four layers, mainly composed of proteinaceous material [21]. The different composition and structure of microalgae cell walls have a strong impact on their integrity and susceptibility of intracellular components to be released during processing. As a result, an incipient amount of work is being developed to explore efficient methods for the disruption of microalgae cell walls and subsequent extraction of intracellular bioactive compounds [22-25]. Amongst the different disruption methods, ultrasound treatments have attracted a great deal of interest since they are able to disrupt cells with less energy loss compared with high-shear force 
methods [26]. The ability of ultrasound treatments to disrupt cell walls from various microalgae species has been shown to be useful to increase the extraction yield of different compounds such as lipids and proteins [22, 27-29]. On the other hand, the structural changes and the release of intracellular components induced by cell wall disruption treatments are also expected to affect the rheology of treated microalgae suspensions.

In this study the rheological properties of aqueous suspensions of three microalgae species, Nannochloropsis gaditana, Scenedesmus almeriensis and Spirulina platensis, were investigated and related to their composition and microstructure. Furthermore, the impact of ultrasound processing on their structuring ability was also studied. To do this, shear viscosity and viscoelasticity measurements, as well as compositional and microstructural analyses, were carried out before and after ultrasound processing. The outcomes of this work give insights into the exploitation of these microalgae species for food, pharma and other technological applications.

\section{Materials and methods}

\subsection{Materials}

Three different microalgae species, i.e. Nannochloropsis gaditana, Spirulina platensis platensis and Scenedesmus almeriensis almeriensis, in the form of dry powders, were kindly donated by Dr. Acién from the University of Almeria (Spain). The Spirulina platensis biomass was produced using a raceway open photobioreactor, while Nannochloropsis gaditana and Scenedesmus almeriensis were produced using closed photobioreactors. The obtained biomass was collected by centrifugation and subjected to freeze-drying. The freezedried samples, coded as Nannochloropsis gaditana, Spirulina platensis and Scenedesmus almeriensis were stored in the fridge until further use. 
Sulphuric acid (99.2-101\%), methanol, sodium carbonate, gallic acid (97.5-102.5\%), potassium persulphate ( $\geq 99 \%$ ), phosphate buffered saline tablets, acetyl chloride, ABTS $((2,2$ '-azino-bis(3-ethylbenzothiazoline-6-sulfonic acid))) ( $\geq 98 \%)$ and 6-hydroxy-2,5,7,8tetramethylchroman-2-carboxylic acid (97\%) were obtained from Sigma-Aldrich (Spain). The Folin-Ciocalteau reagent, modified Lowry reagent and bovine serum albumin were obtained from the "modified Lowry protein assay kit" purchased from Thermo Fisher scientific (Spain).

\subsection{Ultrasound treatment}

The three microalgae species were subjected to an ultrasound treatment, following the protocol previously described in [30]. Briefly, the microalgae powders were dispersed in distilled water at a concentration of $0.4 \mathrm{~g} / \mathrm{L}$. The suspensions were then treated with a UP400S ultrasound equipment (Hielcher $\mathrm{GmbH}$, Germany), applying a power of $400 \mathrm{~W}$ and a frequency of $24 \mathrm{kHz}$ for $5 \mathrm{~min}$. After that, the suspensions were freeze-dried and the resulting powders were stored in the fridge until further use. These samples were coded as Nannochloropsis gaditana-US, Spirulina platensis -US and Scenedesmus almeriensis-US.

\subsection{Preparation of microalgae suspensions}

Microalgae suspensions at different concentrations (1, 5, 10, 15, 20 and $25 \%$ wt.) were prepared by adding the required amount of microalgae powder to milli Q water and gently mixing with a magnetic stirrer, leaving the samples to fully hydrate overnight. After that the rheological, microscopical and particle size experiments were performed.

\subsection{Chemical composition of microalgae before and after ultrasound treatment}




\subsubsection{Carbohydrate content}

The carbohydrate composition in the samples was determined after acid methanolysis of the dry microalgae powders, following the method described in [31]. This technique is not able to cleave crystalline polysaccharides. As cellulose is present in some of the tested microalgae, a two-step sulphuric acid hydrolysis was also performed [32] as to determine the total glucose, and cellulose was calculated as the difference [33]. The samples were then analysed using high performance anion exchange chromatography with pulsed amperometric detection (HPAEC-PAD) with a 940 IC system (Metrohm) equipped with a Matrosep Carb 2 column $(4 \times 250 \mathrm{~mm}$, Metrohm). Control samples of known concentrations of mixtures of glucose, fucose, galactose, arabinose, xylose, mannose or glucuronic were used for calibration (Sigma). All experiments were carried out in triplicate.

\subsubsection{Protein content}

Samples were analysed for total nitrogen content using an Elemental Analyser Rapid N Exceed (Paralab S.L., Spain). About $100 \mathrm{mg}$ of each of the powdered samples were pressed to form a pellet which was then analysed using the Dumas method, which is based on the combustion of the sample and subsequent detection of the released $\mathrm{N}_{2}$ [34]. The total protein content was calculated from the nitrogen content multiplied by a factor of 6.27 in the case of Spirulina platensis and 5.95 for Nannochloropsis gaditana and Scenedesmus almeriensis $[35,36]$.

\subsubsection{Lipid content}

The lipid content was estimated gravimetrically after performing the Soxhlet extraction of ca. $3 \mathrm{~g}$ of dry microalgal material with $800 \mathrm{ml}$ of toluene/ethanol 2:1 (v/v) during $24 \mathrm{~h}$. 


\subsubsection{Ash content}

The ash content was determined by dry biomass calcination of ca. $2 \mathrm{~g}$ of dry microalgae powder in muffle furnace, according to the standard TAPPI T211 om-07 method.

\subsubsection{Phenolic content}

Total phenolic content was estimated by the Folin-Ciocalteau colorimetric assay [37]. Briefly, Folin-Ciocalteau reagent was diluted 1:10 with distilled water and $1 \mathrm{~mL}$ of the final dilution was mixed with $0.2 \mathrm{~mL}$ of the extract sample (microalgae suspensions in distilled water at a concentration of $5 \mathrm{mg} / \mathrm{mL}$ ) at room temperature. Finally, $0.8 \mathrm{~mL}$ of sodium carbonate $(75 \mathrm{mg} / \mathrm{mL})$ were added and the samples were heated up to $50^{\circ} \mathrm{C}$ during 30 minutes. Absorbance values were read at $750 \mathrm{~nm}$. A calibration curve was built using gallic acid as the standard, and the total phenolic content was expressed as mg of gallic acid (GA)/g extract. All determinations were carried out in triplicate.

\subsection{2,2'-azino-bis(3-ethylbenzothiazoline-6-sulfonic acid) $\left(\right.$ ABTS $\left.^{*^{+}}\right)$radical cation}

\section{scavenging activity}

The ABTS $\cdot{ }^{+}$radical cation scavenging activity of the microalgae before and after ultrasound processing was determined according to [37]. Briefly, $0.192 \mathrm{~g}$ of ABTS were dissolved in $50 \mathrm{~mL}$ of PBS at $\mathrm{pH} 7.4$ and mixed with $0.033 \mathrm{~g}$ of potassium persulfate overnight in the dark to yield the $\mathrm{ABTS}^{+}$radical cation. Prior to use in the assay, the ABTS ${ }^{+}$was diluted with PBS for an initial absorbance of $\sim 0.700 \pm 0.02(1: 50$ ratio) at $734 \mathrm{~nm}$, at room temperature. Free radical scavenging activity was assessed by mixing $1.0 \mathrm{~mL}$ diluted $\mathrm{ABTS}^{+}$with $10 \mu \mathrm{L}$ of microalgae suspensions $(5 \mathrm{mg} / \mathrm{mL}$ in water $)$ and monitoring the change in absorbance at 6 minutes. A calibration curve was developed by using 6-hydroxy2,5,7,8-tetramethylchromane-2-carboxylic acid (Trolox). The antioxidant capacity was 
expressed as mg Trolox equivalents (TE)/g extract. All determinations were carried out in triplicate.

\subsection{Fourier transform infrared spectroscopy (FT-IR)}

Freeze-dried microalgae powders were analyzed by FT-IR in attenuated total reflectance (ATR) mode using a Thermo Nicolet Nexus (GMI, USA) equipment. The spectra were recorded at $4 \mathrm{~cm}^{-1}$ resolution in a wavelength range between $400-4000 \mathrm{~cm}^{-1}$ and averaging a minimum of 32 scans.

\subsection{Particle size analysis}

The particle size distribution of microalgae suspensions (5\% in water) before and after ultrasound treatment was determined by laser diffraction using a Malvern Mastersizer 3000 apparatus equipped with a Hydro MV accessory for liquid samples (Malvern Instruments, UK). A refractive index of 1.4683 and an absorption index of 0.01 were used.

\subsection{Optical microscopy}

Aqueous microalgae suspensions at a concentration of $5 \%$ were analysed by optical microscopy. Digital images were taken using an Eclipse 90i Nikon microscope (Nikon corporation, Japan) equipped with 5-megapixels cooled digital colour microphotography camera Nikon Digital Sight DS-5Mc. Acquired images were analysed and processed by using Nis-Elements Br 3.2 Software (Nikon corporation, Japan).

\subsection{Confocal laser scanning microscopy (CLSM)}

Microalgae powders, before and after ultrasound treatment, were dispersed in water to produce $5 \%$ suspensions. Hydrophobic components, such as lipids, were stained with Nile 
Red before being imaged with a CLSM (Leica TCS SP5, Heidelberg, Germany). The objective used was a HCX PL APO CS 63.0x1.20 WATER UV with zoom 4. The $488 \mathrm{~nm}$ line from an argon laser was used for excitation and two channels of were used for emission, 580-606 nm for lipids/hydrophobic components (green) and 670-695 nm for chlorophyll autofluorescence (red). The image resolution was $1024 \times 1024$ pixels.

\subsection{Rheological characterization}

The rheological properties of the microalgae aqueous suspensions were measured at $25^{\circ} \mathrm{C}$ in a strain-controlled ARES G2 rheometer (TA Instruments, New Castle, Delaware, USA) equipped with parallel plates ( $40 \mathrm{~mm}$ in diameter) and a solvent trap to prevent evaporation. The gap was set to $0.5 \mathrm{~mm}$. Shear viscosity measurements were performed from 0.1 to 100 $\mathrm{s}^{-1}$. Small amplitude oscillatory shear experiments were carried out from 0.1 to $10 \mathrm{rad} \cdot \mathrm{s}^{-1}$ at $0.5 \%$ strain. The strain was selected from the lineal viscoelastic region (LVR) obtained from strain sweeps from 0.01 to $1000 \%$ at $10 \mathrm{rad} \cdot \mathrm{s}^{-1}$. Duplicates were measured for each concentration.

\subsection{Statistical analysis}

Data analysis was carried out using Statgraphics Stratus by Statgraphics Technologies, Inc. One-way analysis of variance (ANOVA) was done to determine the significant differences between sample means, at a significance level of $\mathrm{P}<0.05$. Mean comparisons were performed by the Tukey Test.

\section{Results and Discussion}

\subsection{Chemical composition of microalgae before and after ultrasound treatment}


The composition of the three different microalgae species was characterised before and after being subjected to the sonication treatment and the results are summarised in Table 1. As observed, the three different microalgae species presented very distinct composition, with ashes $(\sim 36 \%)$ and proteins $(\sim 27 \%)$ being the main components of Spirulina platensis, while Nannochloropsis gaditana was mainly composed of lipids $(\sim 41 \%)$ and carbohydrates ( $\sim 33 \%)$, and Scenedesmus almeriensis contained a high amount of carbohydrates $(\sim 44 \%)$ and proteins $(\sim 30 \%)$. Although similar trends in terms of major components have been reported in the literature for these species, their specific amounts are highly variable depending on the cultivating and harvesting conditions. For instance, Spirulina platensis microalgae have been described to be mainly composed of proteins, which typically range from $40 \%$ to $70 \%[38,39]$, while carbohydrates $(8-16 \%)$ and lipids $(4-11 \%)$ are minor constituents [38]. However, some studies stated that Spirulina platensis cells cultivated in nitrogen-deficient media $[40,41]$ and genetically-modified species with higher growth rates [42] possess lower protein content than the wild type microalgae. Scenedesmus almeriensis has been reported to be composed mainly of proteins and carbohydrates [43], while similar protein, lipid and ash contents to the ones provided in Table 1 have been previously reported for Nannochloropsis gaditana [44]. It should be noted that very low (or even nil) polyphenol contents were determined for the three microalgae species. This does not necessarily mean that the microalgae did not contain phenolic compounds, as bioactive compounds are mainly located intracellularly and thus, cannot be released towards the liquid medium when the cell walls are intact, as previously pointed out [45].

As shown in Table 1, the application of the ultrasound treatment resulted in a relative increase in the amount of quantified polyphenols. The amount of lipids, on the other hand, was substantially decreased in Nannochloropsis gaditana, while it was not significantly 
affected in Spirulina platensis and Scenedesmus almeriensis. The amount of carbohydrates, proteins and ashes were not determined after the ultrasound treatment since these were based on destructive methods and therefore, the estimated values should be the same irrespective of the sample treatment. Although it should be taken into account that the contents provided in Table 1 are relative amounts (and, therefore, it is not possible to discuss the results in terms of absolute values), the results suggest that the cell wall structure was damaged to some extent by the treatment, enabling the release of a certain amount of intracellular components; however, it seems that the treatment did not produce a complete rupture of the cell walls since only minor compositional changes took place. This is in agreement with a previous study which reported that even though sonication could increase the antioxidant capacity of several microalgae species, other methods such as ultraturrax homogenization were more effective for cell wall disruption [45]. It should also be noted that substances such as pigments and fatty acids may have been degraded upon sonication. In fact, several studies have reported that the pigments present in microalgae are easily degraded due to temperature, light or other microorganisms, while polyunsaturated fatty acids may undergo radicalinduced degradation upon sonication $[46,47]$. This might explain the decrease in the amount of ashes and lipids observed for some of the microalgae species. In particular, the lipid decrease in Nannochloropsis gaditana may be attributed to the higher content in polyunsaturated fatty acids (which are less stable) of this species [48].

The antioxidant activity of the microalgae suspensions was in the range of 20-56 $\mu \mathrm{mol} \mathrm{TE} / \mathrm{g}$ sample. Greater antioxidant capacities than the ones estimated in this work have been described for extracts rich in bioactive components. For instance, antioxidant activities of 100-600 $\mu \mathrm{mol}$ TE/g sample have been described for Scenedesmus obliquus extracts rich in carotenoids [49] and Nannochloropsis gaditana extracts rich in carotenoids, chlorophylls 
and polar lipids have been reported to possess antioxidant capacities of 300-800 $\mu \mathrm{mol} \mathrm{TE} / \mathrm{g}$ sample [50]. This indicates that most of the compounds responsible for the high antioxidant potential of microalgae are intracellular components. As deduced from Table 1, the antioxidant capacity after the sonication treatment, increased in the case of Spirulina platensis while it decreased for Nannochloropsis gaditana and Scenedesmus almeriensis. The explanation for these results is quite complex, since the antioxidant potential may be linked to the presence of polyphenols or other bioactive components, such as sulphated polysaccharides, peptides and aminoacids [51-53]. Thus, it is not possible to unequivocally link the effect in the antioxidant capacity of the samples to the release or degradation of specific components.

Table 1. Composition and antioxidant capacity of the microalgae before and after ultrasound treatment . Data shown as mean $+/-\mathrm{SD}, \mathrm{n}=3$.

\begin{tabular}{|c|c|c|c|c|c|c|}
\hline & $\begin{array}{c}\text { Carbohydrates } \\
(\%)\end{array}$ & $\begin{array}{l}\text { Proteins } \\
\quad(\%)\end{array}$ & Lipids (\%) & Ashes (\%) & $\begin{array}{l}\text { Polyphenols } \\
\text { (mg GA/g } \\
\text { sample) }\end{array}$ & $\begin{array}{c}\text { Antioxidant } \\
\text { Capacity } \\
\text { ABTS } \\
\text { ( } \mu \text { mol TE } / g \\
\text { sample) }\end{array}$ \\
\hline Spirulina platensis & $8.0 \pm 1.2^{\mathrm{a}}$ & $26.8 \pm 0.1^{\mathrm{bc}}$ & $18.8 \pm 5.9^{\mathrm{a}}$ & $36.0 \pm 0.2^{d}$ & $0.9 \pm 0.4^{\mathrm{a}}$ & $56.6 \pm 0.5^{\mathrm{d}}$ \\
\hline $\begin{array}{l}\text { Nannochloropsis } \\
\text { gaditana }\end{array}$ & $32.5 \pm 2.9^{b}$ & $22.8 \pm 0.2^{\mathrm{a}}$ & $40.9 \pm 1.3^{b}$ & $15.6 \pm 0.1^{\mathrm{ab}}$ & n.d. & $31.6 \pm 2.0^{\mathrm{c}}$ \\
\hline $\begin{array}{l}\text { Scenedesmus } \\
\text { almeriensis }\end{array}$ & $44.1 \pm 5.5^{c}$ & $30.2 \pm 0.3^{d}$ & $19.7 \pm 3.8^{\mathrm{a}}$ & $19.4 \pm 0.6^{\mathrm{bc}}$ & n.d. & $20.0 \pm 1.3^{b}$ \\
\hline $\begin{array}{l}\text { Spirulina platensis- } \\
\text { US }\end{array}$ & --- & --- & $13.7 \pm 4.1^{\mathrm{a}}$ & --- & $8.0 \pm 0.9^{b}$ & $77.9 \pm 1.3^{\mathrm{e}}$ \\
\hline $\begin{array}{l}\text { Nannochloropsis } \\
\text { gaditana-US }\end{array}$ & --- & -- & $32.0 \pm 9.6^{\mathrm{a}}$ & -- & $1.6 \pm 0.3^{\mathrm{a}}$ & $23.1 \pm 1.3^{b}$ \\
\hline $\begin{array}{l}\text { Scenedesmus } \\
\text { almeriensis-US }\end{array}$ & --- & --- & $25.8 \pm 7.7^{\mathrm{a}}$ & --- & $1.6 \pm 0.5^{\mathrm{a}}$ & $10.2 \pm 0.9^{\mathrm{a}}$ \\
\hline
\end{tabular}

Values with different letters are significantly different $(\mathrm{p} \leq 0.05)$. 
The FT-IR spectra from the microalgae before and after ultrasound treatment are shown in Figure 1. As observed, the spectra from Scenedesmus almeriensis and Nannochloropsis gaditana were very similar, showing some minor differences in the relative intensity of the peaks appearing within the the region $830-1475 \mathrm{~cm}^{-1}$. In particular, differences could be noted within the range of $1300-1100 \mathrm{~cm}^{-1}$, corresponding to C-O-C stretching vibrations of polysaccharides, which could be ascribed to the distinct carbohydrate composition of Scenedesmus almeriensis and Nannochloropsis gaditana. It should be noted that the band located at $1260 \mathrm{~cm}^{-1}$, characteristic of sulphate ester groups [54], was only visible in Nannochloropsis gaditana, indicating the presence of sulphated polysaccharides, as previously described [15]. The three microalgae species showed the two bands characteristic from the presence of proteins, located at $1640 \mathrm{~cm}^{-1}$ (amide I) and $1540 \mathrm{~cm}^{-1}$ (amide II). The broad band in the range of $3500-3000 \mathrm{~cm}^{-1}$, corresponding to the hydroxyl and $\mathrm{N}-\mathrm{H}$ stretching of carbohydrates and proteins, was also detected in all the samples. The greater lipid and carbohydrate content in Scenedesmus almeriensis and Nannochloropsis gaditana was evidenced by the appearance of the $\mathrm{C}=\mathrm{O}$ stretching band at $1740 \mathrm{~cm}^{-1}$ (not detected in Spirulina platensis) and by the greater intensity of the sharp bands at $2920 \mathrm{~cm}^{-1}$ (associated to $\mathrm{C}-\mathrm{H}$ symmetric stretch) and $2852 \mathrm{~cm}^{-1}$ (associated to $\mathrm{C}-\mathrm{H}$ asymmetric stretch). The latter two bands have been related to the presence of long aliphatic chains of algaenan, i.e. straightchain highly saturated aliphatic compounds, in Nannochloropsis gaditana [55]. Some changes in the FT-IR spectra of the microalgae were seen after the sonication treatment. In the case of Spirulina platensis, the position and relative intensity of some peaks within the region of $800-1200 \mathrm{~cm}^{-1}$ were slightly modified in the ultrasound-treated sample. In particular, the band located at $1420 \mathrm{~cm}^{-1}$, asigned to the $\mathrm{C}-\mathrm{H}$ bending from alkanes [56], became broader after sonication, which may indicate structural changes in the apolar 
fraction. Furthermore, a broad band at $1090-1030 \mathrm{~cm}^{-1}$, attributed to C-O-P stretching [57], became more intense in the treated sample, which could be related to the release of small peptides. Moreover, a clear change in the $\mathrm{O}-\mathrm{H}$ and $\mathrm{N}-\mathrm{H}$ stretching band (at $\sim 3000 \mathrm{~cm}^{-1}$ ) was seen upon the ultrasound treatment. Specifically, this band appeared sharper, which is typical of protein-rich spectra, probably indicating ultrasound-induced protein extraction, as previously described in different aquatic biomass materials $[58,59]$.

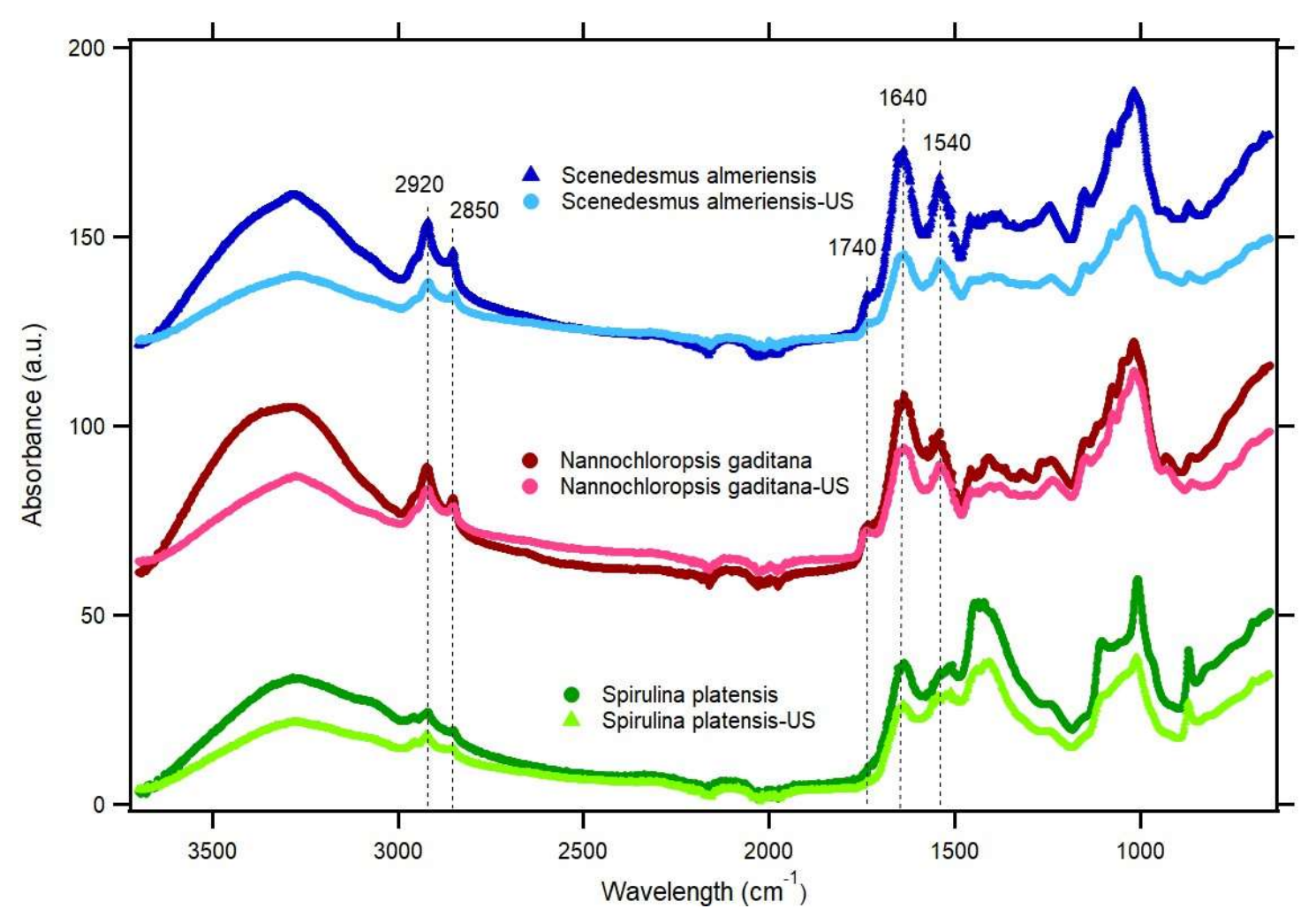

Figure 1. ATR-FTIR spectra from microalgae before and after ultrasound treatment.

\subsection{Carbohydrate composition}

The cell walls from most microalgae species are known to be mainly composed of polysaccharides. The specific carbohydrate composition is crucial to determine the integrity of cell walls and their susceptibility to disruption upon different treatments $[24,25,60]$. Thus, the carbohydrate composition of the three microalgae used in this work was studied 
and the results are compiled in Table 2 . The most abundant carbohydrates in most microalgae species are mainly glucose $(21 \%-87 \%)$, galactose $(1 \%-20 \%)$, and mannose $(2 \%-46 \%)$ and varying amounts $(0 \%-17 \%)$ of arabinose, fucose, rhamnose, ribose, and xylose [35]. The very low carbohydrate content in Spirulina platensis (about $8 \%$ of the total mass) was represented by glucose and minor amounts of galactose and rhamnose, in agreement with previous literature $[61,62]$. The glucose content is most probably derived from an energy reserve, glycogen-type glucan $[63,64]$, while galactose and rhamnose derive from exopolysaccharides $[65,66]$. The rhamnose-containing exopolysaccharide, often described as spirulan, has been attributed a relatively high molecular weight, a pseudoplastic, polyelectrolytic nature, besides several health-promoting properties $[67,68]$. The minor presence of this component might nevertheless contribute to the rheological properties of the suspensions. The low carbohydrate content in Spirulina platensis is not surprising, since these microalgae are known to present thin and fragile peptidoglycan cell walls [69]. In the case of Nannochloropsis gaditana, a relatively high amount of cellulose was present, as opposed to the other two microalgae. Nannochloropsis spp. microalgae have bilayered cell wall structure consisting of a cellulosic inner wall which is protected by an outer hydrophobic algaenan layer [55]. Algaenan consists of aliphatic, partially esterified carbohydrates of different length, which are not accounted for in the current analysis [70]. The non-cellulosic glucose units may arise from the energy reserve glucan chrysolaminarin, while minor contents of galactose, manose and rhamnose in similar ratios have also been reported to be present as part of the cell wall [71-73]. In contrast, Scenedesmus almeriensis was mainly composed of glucose, mannose and galactose. Several Scenedesmus species have been shown to possess a rigid wall constituted of glucose, mannose and galactose [74], while low molecular weight exopolysaccharides have been reported to contain fucose, rhamnose and glucosamine sugar units [75] and promote flocculation, foaming and adhesion $[75,76]$. 
Glucose units can also arise from a starch-like reserve polysaccharide [73]. The higher carbohydrate content in Nannochloropsis gaditana and Scenedesmus almeriensis can be correlated to their more rigid cell wall structures, less susceptible to damage by sonication than those found in Spirulina platensis. This would explain the greater release of polyphenols in the latter after the ultrasound treatment.

Table 2. Carbohydrate composition of the microalgae. Data shown as mean $+/-\mathrm{SD}, \mathrm{n}=3$.

\begin{tabular}{|l|c|c|c|}
\cline { 2 - 4 } \multicolumn{1}{c|}{} & \multicolumn{3}{c|}{ Carbohydrate concentration (mg/g) } \\
\cline { 2 - 4 } \multicolumn{1}{c|}{} & $\begin{array}{c}\text { Spirulina } \\
\text { platensis }\end{array}$ & $\begin{array}{c}\text { Nannochloropsis } \\
\text { gaditana }\end{array}$ & $\begin{array}{c}\text { Scenedesmus } \\
\text { almeriensis }\end{array}$ \\
\hline Fucose & $5 \pm 1$ & $7 \pm 1$ & $6 \pm 2$ \\
\hline Rhamnose & $11 \pm 1$ & $10 \pm 1$ & $<1$ \\
\hline Arabinose & $<1$ & $2 \pm 1$ & $19 \pm 3$ \\
\hline Xylose & $5 \pm 1$ & $31 \pm 1$ & $303 \pm 37$ \\
\hline Galactose & $10 \pm 1$ & $147 \pm 5$ & $11 \pm 2$ \\
\hline NCG $\left.{ }^{*}\right)$ & $30 \pm 2$ & $91 \pm 5$ & $77 \pm 7$ \\
\hline Cellulose & $3 \pm 1$ & $25 \pm 2$ & $9 \pm 2$ \\
\hline Mannose & $9 \pm 3$ & $9 \pm 1$ & \\
\hline $\begin{array}{l}\text { Uronic } \\
\text { acids }\end{array}$ & $6 \pm 2$ & & \\
\hline
\end{tabular}

${ }^{(*)}$ NCG: Non-cellulosic glucose

\subsection{Particle morphology and size distribution of aqueous suspensions}

Light and confocal laser scanning microscopy analyses were carried out to characterise the morphology of microalgae cells in aqueous suspensions. Note that in the micrographs from confocal laser scanning microscopy auto-fluorescence from chloroplasts is shown in red and 
hydrophobic components which stained for Nile Red, such as lipids, are shown in green. In the case of Spirulina platensis (Figures 2A and 2G), different types of particles could be visualised: oval-shaped cells (average cell size of $4.6 \mathrm{~nm}$ ), tubullar particles (pointed out with arrow in Figure 2A) and a background of amorphous material. A tubular morphology has been consistently reported in the literature for different Spirulina species [77-79], and has been ascribed to the association of cells attached by their walls to form colonies. The fact that unicellular fragments were mainly observed could be due to disassociation of individual cells as a result of the stirring process applied during sample preparation. Nannochloropsis gaditana cells presented a globular shape (cf. Figures 2B and 2H) similar to that previously reported for other Nannochloropsis species [80, 81], with an average cell diameter of $1.9 \mu \mathrm{m}$ (cf. Table 3). In contrast, Scenedesmus almeriensis cells presented a more oval-like morphology with a larger average cell size of $4.8 \mu \mathrm{m}$ (cf. Figures 2C and $2 \mathrm{I})$, in agreement with previous studies $[82,83]$. As deduced from the images corresponding to the ultrasound-treated microalgae (Figures 2D-F and $2 \mathrm{~J}-\mathrm{L}$ ), cell disruption did not appear to take place, as most cells seemed to remain intact and the average cell size was not significantly affected (cf. Table 3). However, in the case of Nannochloropsis gaditana and Scenedesmus almeriensis, individual cells appeared to be more homogeneously dispersed in the ultrasound-treated material, as opposed to the untreated microalgae, where the cells tended to be associated in small clusters. The Spirulina platensis cells seemed to be surrounded by extracellular material, likely containing lipids, represented in green in the confocal images (Figure 2G). Unstained samples of Spirulina platensis did not show any fluorescence in the amorphous material, hence excluding the possibility of the green colour coming from auto-fluorescence. This background network was disrupted by the ultrasound treatment (Figure 2D). 

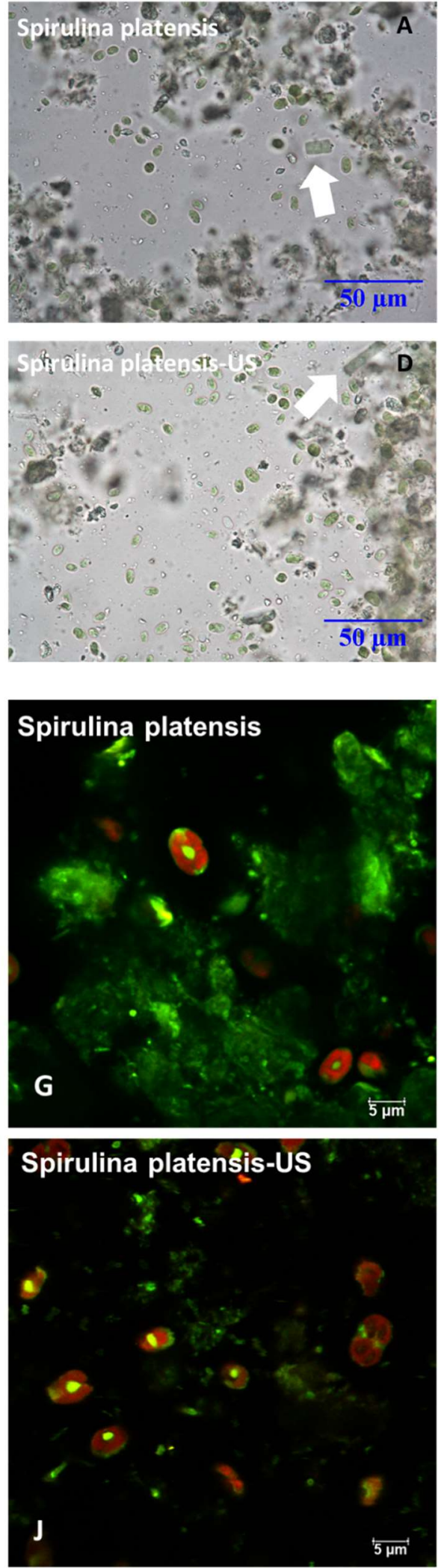
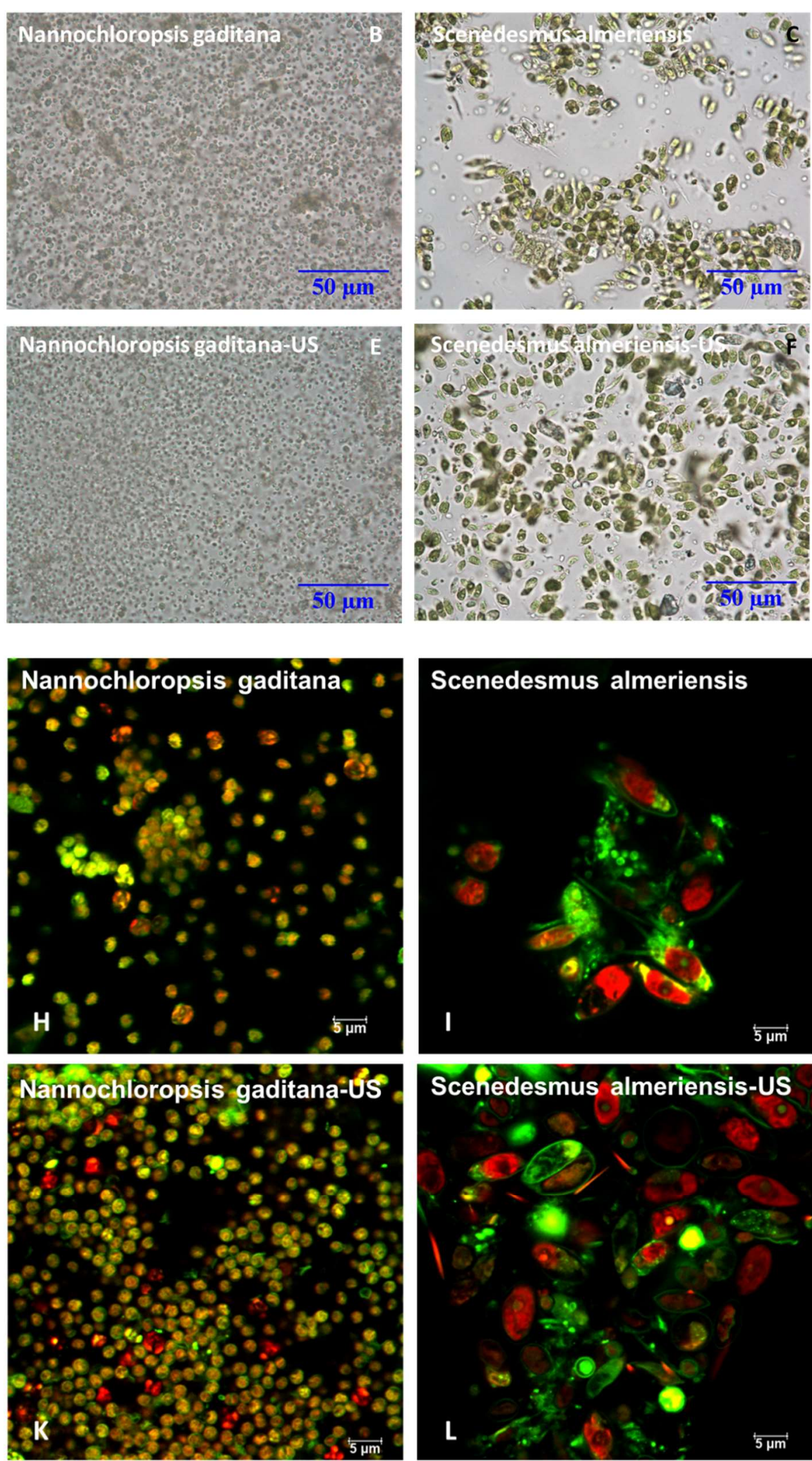

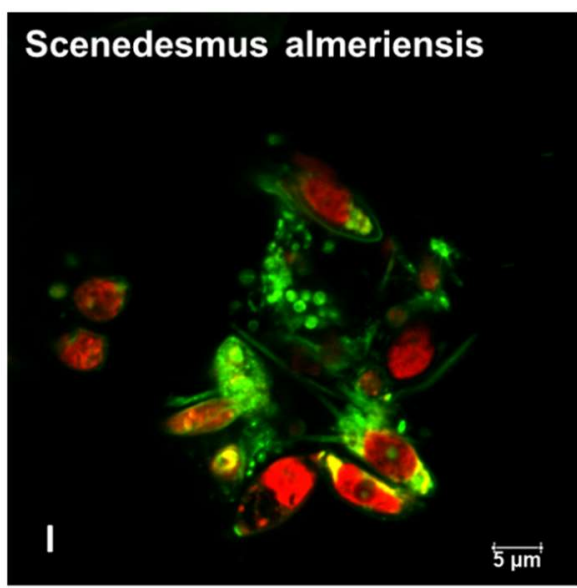

Scehedesmus almeriensis-US

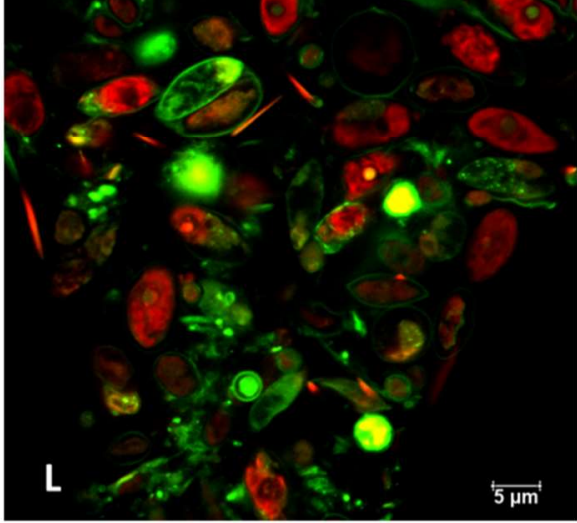


Figure 2. Light microscopy (A-F) and confocal scanning laser microscopy (G-L) images of $5 \%$ microalgae suspensions in water. CSLM shows autofluorescence from chlorophyll (red) and lipids/hydrophobic components (green).

The particle size distribution and the average particle size and specific surface area were determined by laser diffraction (cf. Figure 3 and Table 3). The estimated values for the surface weighted mean particle size $(\mathrm{D}[3,2])$ were within the same range as the sizes estimated from the light microscopy images. It should be noted that the $\mathrm{D}[3,2]$ values were slightly larger likely due to the presence of extracellular material attached to the cell surface, which is not accounted for when estimating particle size from light microscopy. The smaller average particle size corresponded to the Nannochloropsis gaditana microalgae, which also presented a larger specific surface area. On the other hand, the sonication treatment did not have a significant impact on the average particle size of Spirulina platensis and Nannochloropsis gaditana cells, in agreement with the microscopy results, while a minor effect was observed for Scenedesmus almeriensis cells, with a reduction in their surface weighted mean size and increasing their specific surface area. The obtained particle size distributions (cf. Figure 3) indicated the coalescence of microalgae cells into clusters, fact that has been previously reported in the literature for several microalgae species [84-86]. While the Spirulina platensis and Scenedesmus almeriensis cells seemed to flocculate forming a major population of clusters with sizes of ca. 33-44 $\mu \mathrm{m}$ and 14-18 $\mu \mathrm{m}$, respectively, a more heterogeneous size distribution was observed in the case of Nannochloropsis gaditana. In that case, three different populations with size ranges of ca. 1-2 $\mu \mathrm{m}$ (single cells), 65-88 $\mu \mathrm{m}$ and 462-628 $\mu \mathrm{m}$ were detected in the untreated microalgae. After subjecting the Nannochloropsis gaditana cells to the ultrasound treatment, the distribution of the two larger-sized populations was significantly modified, with most of the 
clusters being within the range of $65-88 \mu \mathrm{m}$. Although less evident, the size distribution in Scenedesmus almeriensis was also modified after the sonication treatment, suggesting a fewer amount of larger sized clusters. The greater extent of cluster disaggregation in Nannochloropsis gaditana and Scenedesmus almeriensis, as compared with Spirulina platensis cells, may be related to the presence of extracellular material, acting as a glue, in the latter. 

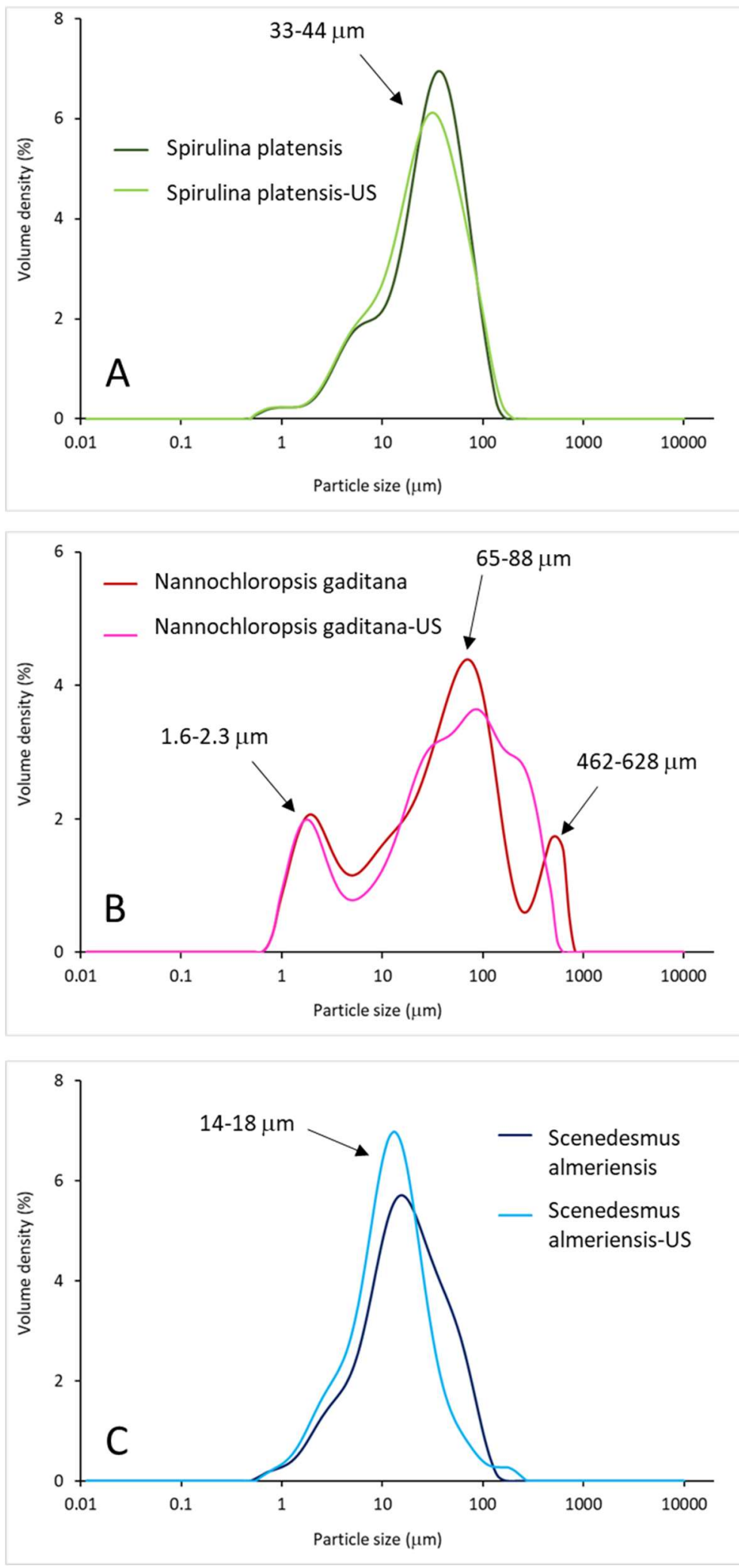

Figure 3. Particle size distribution of untreated and ultrasound-treated microalgae. (A) Spirulina platensis, (B) Nannochloropsis gaditana and (C) Scenedesmus almeriensis. 
Table 3. Specific surface area and particle size determined from the DLS measurements (D $[3,2]$ : surface weighted mean; D [4,3]: volume weighted mean) and from the optical microscope images (D). Data shown as mean $+/-\mathrm{SD}, \mathrm{n}=3$.

\begin{tabular}{|l|c|c|c|c|}
\cline { 2 - 5 } \multicolumn{1}{l|}{} & $\begin{array}{c}\text { Specific } \\
\text { surface area } \\
\left(\mathrm{m}^{2} / \mathrm{g}\right)\end{array}$ & $\mathrm{D}[3,2](\mu \mathrm{m})$ & $\mathrm{D}[4,3](\mu \mathrm{m})$ & $\mathrm{D}(\mu \mathrm{m})$ \\
\hline Spirulina platensis & $0.52 \pm 0.01^{\mathrm{a}}$ & $11.5 \pm 0.3^{\mathrm{c}}$ & $32 \pm 2^{\mathrm{ab}}$ & $4.6 \pm 2.0^{\mathrm{a}}$ \\
\hline Nannochloropsis gaditana & $0.84 \pm 0.02^{\mathrm{cd}}$ & $7.2 \pm 0.2^{\mathrm{a}}$ & $83 \pm 9^{\mathrm{c}}$ & $1.9 \pm 0.6^{\mathrm{a}}$ \\
\hline Scenedesmus almeriensis & $0.74 \pm 0.02^{\mathrm{b}}$ & $8.1 \pm 0.2^{\mathrm{b}}$ & $22 \pm 1^{\mathrm{ab}}$ & $4.8 \pm 1.2^{\mathrm{a}}$ \\
\hline Spirulina platensis-US & $0.55 \pm 0.03^{\mathrm{a}}$ & $10.8 \pm 0.6^{\mathrm{c}}$ & $31 \pm 3^{\mathrm{b}}$ & $3.4 \pm 1.9^{\mathrm{a}}$ \\
\hline $\begin{array}{l}\text { Nannochloropsis gaditana- } \\
\text { US }\end{array}$ & $0.80 \pm 0.02^{\mathrm{c}}$ & $7.5 \pm 0.2^{\mathrm{ab}}$ & $80 \pm 4^{\mathrm{c}}$ & $1.5 \pm 0.5^{\mathrm{a}}$ \\
\hline Scenedesmus almeriensis-US & $0.89 \pm 0.01^{\mathrm{d}}$ & $6.8 \pm 0.1^{\mathrm{a}}$ & $17 \pm 1^{\mathrm{a}}$ & $5.1 \pm 1.7^{\mathrm{a}}$ \\
\hline
\end{tabular}

Values with different letters are significantly different $(\mathrm{p} \leq 0.05)$.

\subsection{Rheological properties of aqueous suspensions}

\subsubsection{Flow behaviour of microalgae suspensions}

The flow behaviour of microalgae suspensions at different concentrations is shown in Figure 4, represented as log-log plots of shear viscosity vs. shear rate. As it can be observed, at 1 wt.\% concentration, the suspensions of the three species showed a Newtonian behaviour, with viscosity values close to that of water $(1 \mathrm{mPa} \cdot \mathrm{s})$. As the concentration increased, the behaviour shifted from Newtonian to shear thinning (i.e. decreased viscosity with increased shear). This was already apparent at $5 \mathrm{wt} . \%$ for Spirulina platensis (Figure 4A), whilst for Nannochloropsis gaditana (Figure 4B) and Scenedesmus almeriensis (Figure 4C) shear thinning behaviour was observed at higher concentrations of $15 \mathrm{wt} . \%$ total solids. Previous studies have shown that Nannochloropsis spp. suspensions behave as shear thinning fluids 
at 25 wt. $\%[18,87]$ whilst at 8 wt.\% they have Newtonian behaviour [15], indicating that the critical concentration lays somewhere between 8 wt.\% and 25 wt.\%, in agreement with our results. Shear thinning behaviour could be due to interactions between microalgae cells (intact or broken) and soluble polymers released from the microalgae into the liquid phase. The presence of this shear thinning behaviour at lower concentrations for Spirulina platensis could be due to the extracellular polysaccharides (such as spirulan) and lipids observed by CSLM (Figure 2G).

Table 4 shows the fitting parameters of the shear stress vs. shear rate curves for $25 \mathrm{wt} . \%$ total solids using a power-law model. All the suspensions showed $\mathrm{n}<1$, with values between 0.27 and 0.59 . The lowest values corresponded to the Spirulina platensis suspension, with $\mathrm{n}=0.27 \pm 0.01$. Spirulina platensis and Scenedesmus almeriensis showed a higher consistency compared to Nannochloropsis gaditana suspensions, suggesting that the contribution of hydrodynamic forces was higher in the former. In Figure 4D it can be observed that the viscosity vs. concentration behaviour of the three microalgae species falls under a master curve up to $20 \mathrm{wt} . \%$, whilst at $25 \mathrm{wt} . \%$ the curves start to deviate from each other, with Nannochloropsis gaditana having the lowest viscosity and Scenedesmus almeriensis the highest viscosity. The increase of viscosity with concentration follows an exponential growth with an exponent of $n=0.28 \pm 0.01\left(R^{2}=0.98 \pm 0.01\right)$. Broader particle size distributions typically lead to lower viscosities, since small particles can fit in the voids created by larger particles. Furthermore, they will act as a lubricant; when flow starts, the large particles will flow over the small particles decreasing the viscosity of the system. In the case of microalgae, the shape, density, surface roughness and deformability of the cells would influence the interaction between particles and, thus, the maximum volume occupied by the particles. On the one hand, Nannochloropsis gaditana presented the more rigid cell 
walls, based on the measured cellulose content (Table 2) and in agreement with previous studies [20]; therefore, Nannochloropsis gaditana cells would lead to high particle phase volumes since the particles could not deform to accommodate for other particles. On the other hand, Nannochloropsis gaditana cells had the smallest average particle size and the broadest particle size distribution (cf. Table 3 and Figure 3) and this could lead to a lower particle phase volume and, thus, to lower viscosity. Scenedesmus almeriensis had similar average particle size and particle size distribution than Spirulina platensis; however, the higher viscosity of the former indicates that the particle volume fraction occupied by Scenedesmus almeriensis cells is larger than that of Spirulina platensis cells. This could be due to the more rigid cell walls in Scenedesmus almeriensis (cf. Table 2). To sum up, and similarly to what has been shown for suspensions of other plant materials such as fruits and vegetables [88-90], at low concentrations, the rheology of microalgae suspensions is mainly controlled by the rheology of the liquid phase and the particle volume fraction [91]; whilst at high concentrations the viscosity depends on the deformability of closely-packed microalgae cells, which in turn is a function of cell wall composition and structure. 

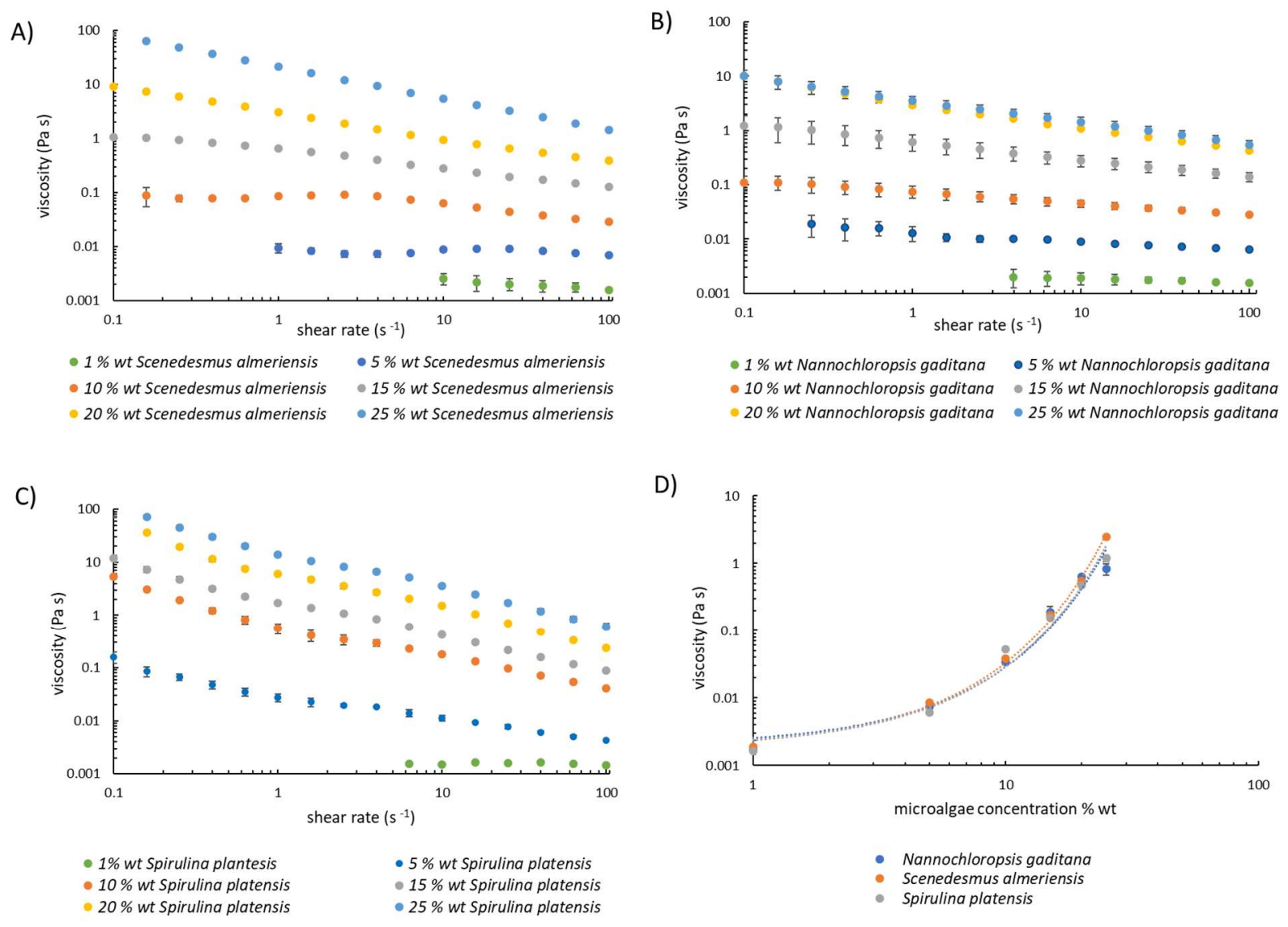

Figure 4. Shear viscosity at different concentrations for A) Spirulina platensis, B) Nannochloropsis gaditana and C) Scenedesmus almeriensis. The change from Newtonian to shear thinning behaviour is clearly seen at different concentrations for each species. D) Shear viscosity (selected at $40 \mathrm{~s}^{-1}$ ) as a function of microalgae concentration (\% wt.) and master curve $\left(n=0.28 \pm 0.01, R^{2}=0.98 \pm 0.01\right)$ showing a general behaviour for these three microalgae species with deviation at higher concentrations. Data shown as mean +/-SD at each shear rate, $n=3$.

Table 4. Parameters obtained from fitting the log-log shear stress vs shear rate plots to a Power Law $\left(\sigma=K \dot{\gamma}^{n}\right)$ model. $\sigma$ represents the shear stress, $K$ the consistency coefficient, $\dot{\gamma}$ the shear rate and $\mathrm{n}$ the flow index. Parameters obtained from fitting the elastic modulus 
$G^{\prime}$ vs angular frequency $w$ to power law model $\left(G^{\prime}=a w^{c}\right)$. The quality of the fitting is represented by $\mathrm{R}^{2}$. nd=not detected. Tan(delta) values of the $25 \mathrm{wt} . \%$ suspensions.

\begin{tabular}{|l|c|c|c|c|c|c|c|}
\cline { 2 - 8 } \multicolumn{1}{c|}{} & \multicolumn{3}{c|}{$\sigma=K \dot{\gamma}^{n}}$, & \multicolumn{3}{c|}{$G^{\prime}=a w^{b}$} \\
\cline { 2 - 8 } & $\begin{array}{c}\text { Consistency } \\
\text { coefficient } \\
\left(\mathrm{Pa} \mathrm{s}^{-\mathrm{n}}\right)\end{array}$ & $\begin{array}{c}\text { Flow } \\
\text { behaviour (-) }\end{array}$ & $\mathrm{R}^{2}$ & $\mathrm{a}$ & $\mathrm{b}$ & $\mathrm{R}^{2}$ & $\begin{array}{c}\text { Tan (delta) at } \\
0.5 \mathrm{rad} \mathrm{s}^{-1} \\
\mathrm{G}^{\prime \prime} / \mathrm{G}^{\prime}\end{array}$ \\
\hline $\begin{array}{l}\text { Spirulina } \\
\text { platensis }\end{array}$ & $17.40 \pm 1.32$ & $0.27 \pm 0.01$ & 0.98 & $170 \pm 12.5$ & $0.16 \pm 0.02$ & 0.97 & $0.25 \pm 0.08$ \\
\hline $\begin{array}{l}\text { Nannochloropsis } \\
\text { gaditana }\end{array}$ & $3.62 \pm 0.88$ & $0.59 \pm 0.01$ & 0.99 & $5.70 \pm 0.90$ & $0.42 \pm 0.05$ & 0.98 & $1.02 \pm 0.00$ \\
\hline $\begin{array}{l}\text { Scenedesmus } \\
\text { almeriensis }\end{array}$ & $21.40 \pm 0.50$ & $0.41 \pm 0.01$ & 0.99 & $55.6 \pm 7.01$ & $0.40 \pm 0.11$ & 0.97 & $0.72 \pm 0.13$ \\
\hline
\end{tabular}

\subsubsection{Viscoelastic properties of microalgae suspensions}

To better understand the differences in rheological properties at high concentrations, the viscoelastic properties of the suspensions at $25 \mathrm{wt} . \%$ were investigated. Figure 5 shows the viscoelastic moduli $\left(\mathrm{G}^{\prime}\right.$ and $\left.\mathrm{G}^{\prime \prime}\right)$ vs. frequency. At this concentration, the Spirulina platensis suspensions showed an elastic behaviour $\left(\mathrm{G}^{\prime}>\mathrm{G}^{\prime \prime}\right)$ over the whole range of frequencies. Scenedesmus almeriensis suspensions also showed a predominant elastic behaviour, especially at higher frequencies, whilst Nannochloropsis gaditana showed a slightly predominant viscous behaviour $\left(\mathrm{G}^{\prime}<\mathrm{G}^{\prime \prime}\right)$ at high frequencies. The frequency dependency of $\mathrm{G}^{\prime}$ was fit to a power law model $\left(G^{\prime}=a w^{b}\right)$ and values of fitting parameters are shown in Table 4. Suspensions of Nannochloropsis gaditana and Scenedesmus almeriensis showed similar frequency dependence with $b$ values of ca. 0.40, whilst Spirulina platensis suspensions showed a lower frequency dependence with an exponent of 0.16 . The exponent value lower than 2 as well as the $\mathrm{G}^{\prime}>\mathrm{G}^{\prime \prime}$ and $\tan ($ delta $)<1$ indicate that the Spirulina platensis suspension behaved as a weak gel, while the Nannochloropsis gaditana suspension showed a predominant viscous behaviour $(\tan ($ delta $)>1)$ [92]. The values of the fitting 
parameter $a$ were in the order Spirulina platensis $>$ Scenedesmus almeriensis $>$ Nannochloropsis gaditana, suggesting that the strongest network was present in the Spirulina platensis suspensions. On the contrary, the weakest network was present in the Nannochloropsis gaditana suspensions, in agreement with their most viscous nature.

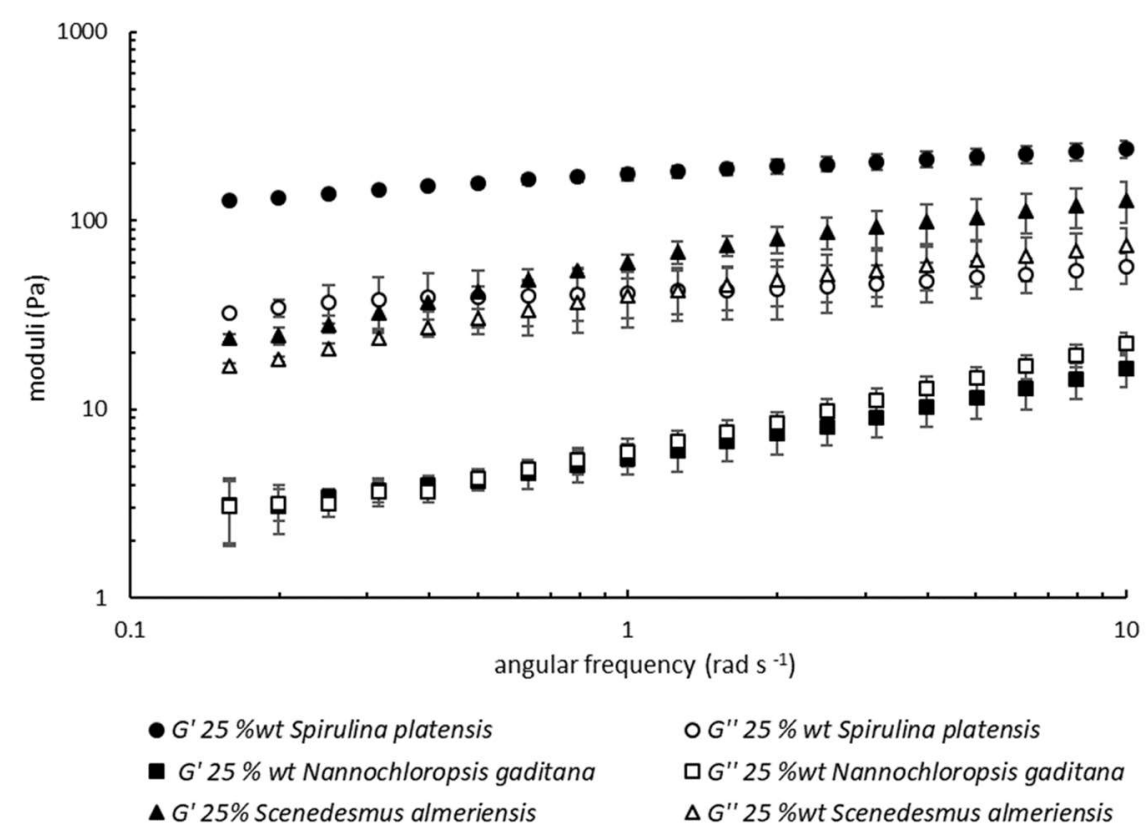

Figure 5. Frequency sweeps of $25 \%$ wt. suspensions of Spirulina platensis, Nannochloropsis gaditana and Scenedesmus almeriensis. Data shown as mean +/-SD at each angular frequency, $\mathrm{n}=3$.

The complexity of these materials makes it difficult to underpin the main reason for having networks of different strength, since covalent, non-covalent, as well as electrostatic interactions, might be occurring between the microalgae cells and/or with the extracellular components in the liquid phase. Based on the composition, the presence of exopolysaccharides (either loosely attached to the cell wall or released to the liquid phase), which contained rhamnose and galactose in Spirulina platensis and rhamnose and fucose in 
Scenedesmus almeriensis, could explain the stronger nature of the networks in these suspensions, whilst the rigidity of the Nannochloropsis gaditana cells, mainly containing cellulose, would lead to weaker networks.

\subsubsection{Impact of ultrasound processing on rheological properties}

Compositional and microscopy analyses suggested that ultrasound processing even though not disintegrating the cell walls, changed the microalgae suspensions to some extent. In Nannochloropsis gaditana and Scenedesmus almeriensis, cell clusters were separated into single cells (cf. Figure 2) and intracellular components (like proteins or peptides) were released towards the liquid medium. The effect of this on the rheological properties of aqueous suspensions was also investigated, and the results for $25 \mathrm{wt} \%$ suspensions of ultrasound-treated microalgae are presented in Figure 6. The ultrasound treatment did not have a significant impact on the viscosity of Spirulina platensis suspensions, whilst it increased the viscosity of Nannochloropsis gaditana suspensions and decreased the viscosity of Scenedesmus almeriensis suspensions. The increase in viscosity could be related to a higher viscosity of the liquid phase due to the release of cell components in the case of Nannochloropsis gaditana, whilst in Scenedesmus almeriensis a narrower particle size distribution as result of ultrasound processing (cf. Figure 3), could explain the lowest viscosity of these suspensions. In terms of viscoelastic properties, ultrasounds increased the G' (elastic modulus) and G', (viscous modulus) of Spirulina platensis and Nannochloropsis gaditana, whilst a trend towards a decrease in the viscoelastic moduli was observed for the Scenedesmus almeriensis suspensions. An increase in the interactions between cells and the cell components released to the liquid phase could contribute to a higher viscoelasticity in the Nannochloropsis gaditana and Spirulina platensis suspensions. On the other hand, the disaggregation of cell clusters could explain the weakening effect in the Scenedesmus 
almeriensis suspensions, due to the reduction of cell-cell interactions, which contribute to the elasticity of the system.
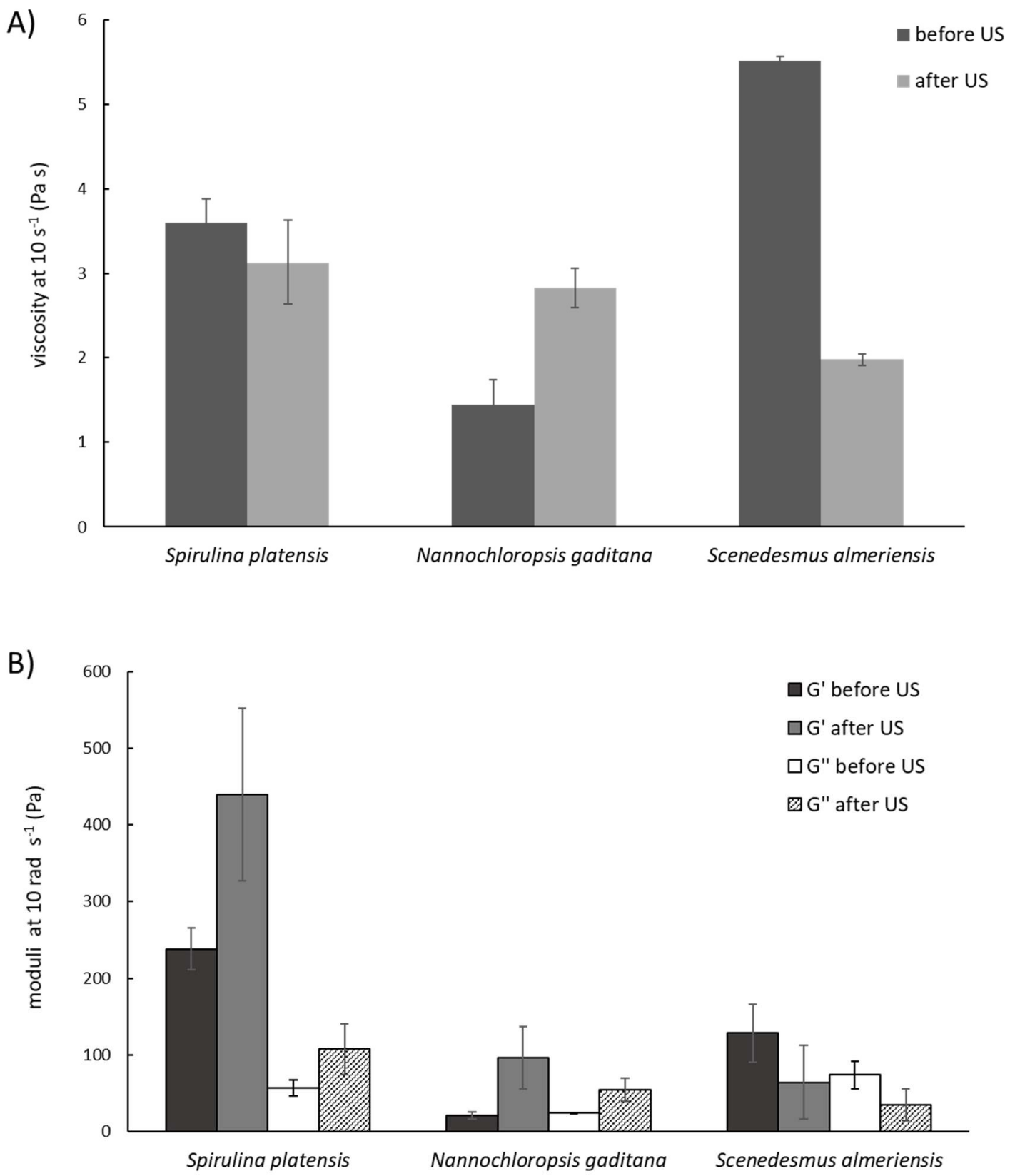

Figure 6. A) Viscosity of $25 \%$ wt. microalgae suspensions (at $10 \mathrm{~s}^{-1}$ ) before and after ultrasound treatment. B) Viscoelastic moduli of 25\% wt. microalgae suspensions, G' (elastic 
modulus) and G', (viscous modulus) selected at $10 \mathrm{rad} \mathrm{s}^{-1}$, as result of ultrasound treatment. Data shown as mean $+/-\mathrm{SD}, \mathrm{n}=3$.

\section{Conclusions}

The rheological properties of aqueous suspensions from three microalgae species, before and after being subjected to an ultrasound treatment, were investigated and related to their composition and physico-chemical properties. The composition of the three microalgae was substantially different: Spirulina platensis was mainly composed of ashes $(\sim 36 \%)$ and proteins ( $\sim 27 \%$ ), while Scenedesmus almeriensis ( $\sim 44 \%$ carbohydrates and $\sim 32 \%$ proteins) and Nannochloropsis gaditana ( $\sim 41 \%$ lipids and $\sim 33 \%$ carbohydrates) were richer in carbohydrates. In particular, Nannochloropsis gaditana contained a relatively high amount of cellulose, providing greater rigidity to the cell walls. On the other hand, exopolysaccharides were mainly composing the carbohydrate fraction in Spirulina platensis and Scenedesmus almeriensis. The presence of extracellular material was especially evident in the Spirulina platensis microalgae; this explained the fact that Spirulina platensis suspensions presented shear thinning behaviour at lower concentrations than Scenedesmus almeriensis and Nannochloropsis gaditana, as well as the weak gel behaviour of the 25 wt. $\%$ Spirulina platensis suspensions. The viscosity of the three microalgae species followed the same master curve up to $20 \mathrm{wt}$. \% total solids; however, at $25 \mathrm{wt} . \%$ the curves started to deviate from each other, with Nannochloropsis gaditana having the lowest viscosity and Scenedesmus almeriensis the highest viscosity. These results suggest that at low concentrations the rheology is mainly controlled by the liquid phase and the particle volume fraction; whilst at high concentrations the viscosity of the microalgae suspensions depends on the deformability of closely-packed microalgae cells, determined by their cell wall composition and structure. Remarkably, the different behaviour of 25 wt. \% Spirulina 
platensis (weak gel behaviour) and Nannochloropsis gaditana (viscous liquid behaviour) suspensions, suggests potential different applications for these two species.

The application of the ultrasound treatment did not produce cell wall disruption, but it seemed to promote the release of a certain amount of intracellular components; however, some of these components, such as the more unstable polyunsaturated fatty acids, may have been degraded upon the treatment and, thus, only a minor effect in the antioxidant capacity of the microalgae was observed. The treatment did not significantly impact the particle size of the microalgae, producing only a minor decrease in the cell size of Scenedesmus almeriensis cells. On the other hand, ultrasounds were able to disrupt the cells' clusters in Scenedesmus almeriensis and Nannochloropsis gaditana. All these factors affected the rheology of the ultrasound-treated suspensions, increasing the viscosity of Nannochloropsis gaditana suspensions, while the viscosity of Scenedesmus almeriensis suspensions was reduced. Furthermore, the viscoelastic moduli of Spirulina platensis and Nannochloropsis gaditana suspensions were increased, which could be attributed to greater interactions between the cells and the extracellular material; however, the heterogeneity and complexity of these systems makes it difficult to correlate the rheological changes to one single factor.

These results demonstrate that it is possible to produce microalgae suspensions with very different rheological properties, for specific applications, by selecting the appropriate species. Moreover, the application of mild ultrasound treatments may also be an efficient approach to modify the rheological properties of microalgae suspensions.

\section{Acknowledgements}


This work was supported by the COST Action ES1408 European network for algalbioproducts (EUALGAE).

\section{Conflict of interest}

The authors declare that they have no conflict of interest.

\section{Informed consent, human or animal rights}

No conflicts, informed consent, human or animal rights applicable.

\section{Declaration of authors agreement}

The authors agree to authorship and submission of the manuscript for peer review.

\section{CRediT authorship contribution statement}

Marta Martínez-Sanz: Conceptualization, Methodology, Investigation, Formal analysis, Resources, Writing - Original Draft, Writing - Review \& Editing, Funding acquisition, Supervision. Agustín Garrido-Fernández: Investigation, Methodology, Formal analysis. Ana Mijlkovic: Investigation, Methodology, Formal analysis. Annika Krona: Investigation, Methodology, Formal analysis. Antonio Martínez-Abad: Investigation, Methodology, Formal analysis, Writing - Review \& Editing. José M. Coll-Marqués: Investigation, Methodology, Formal analysis. Amparo López-Rubio: Conceptualization, Resources, Writing - Review \& Editing, Funding acquisition, Supervision. Patricia LopezSanchez: Conceptualization, Investigation, Formal analysis, Funding acquisition, Resources, Writing - Original Draft, Writing - Review \& Editing, Supervision.

\section{References}


[1] R. Harun, M. Singh, G.M. Forde, M.K. Danquah, Bioprocess engineering of microalgae to produce a variety of consumer products, Renewable and Sustainable Energy Reviews, 14 (2010) 1037-1047.

[2] P. Spolaore, C. Joannis-Cassan, E. Duran, A. Isambert, Commercial applications of microalgae, Journal of Bioscience and Bioengineering, 101 (2006) 87-96.

[3] T. Chacón-Lee, G.E. González-Mariño, Microalgae for "healthy" foods-possibilities and challenges, Comprehensive reviews in food science and food safety, 9 (2010) 655-675. [4] M. Fradique, A.P. Batista, M.C. Nunes, L. Gouveia, N.M. Bandarra, A. Raymundo, Incorporation of Chlorella vulgaris and Spirulina platensis maxima biomass in pasta products. Part 1: Preparation and evaluation, Journal of the Science of Food and Agriculture, 90 (2010) 1656-1664.

[5] B.F. Lucas, M.G. de Morais, T.D. Santos, J.A.V. Costa, Spirulina platensis for snack enrichment: Nutritional, physical and sensory evaluations, LWT, 90 (2018) 270-276. [6] O. Morsy, A.E.-D. Sharoba, B. Hem, Production and evaluation of extruded food products by using Spirulina platensis algae, Annals of Agric. Sci., Moshtohor ISSN, (2014) 1110-0419.

[7] T.D. Santos, B.C.B.d. Freitas, J.B. Moreira, K. Zanfonato, J.A.V. Costa, Development of powdered food with the addition of Spirulina platensis for food supplementation of the elderly population, Innovative Food Science \& Emerging Technologies, 37 (2016) 216220.

[8] M. Martínez-Sanz, M.J. Fabra, L. G. Gómez-Mascaraque, A. López-Rubio, Structural effects of microalgae additives on the starch gelatinisation process, Food Hydrocolloids, 77 (2018) 257-269.

[9] M. Martínez-Sanz, E. Larsson, K.B. Filli, C. Loupiac, A. Assifaoui, A. López-Rubio, P. Lopez-Sanchez, Nano-/microstructure of extruded Spirulina platensis/starch foams in relation to their textural properties, Food Hydrocolloids, (2020) 105697.

[10] C.W. Macosko, R.G. Larson, Rheology: principles, measurements, and applications, (1994).

[11] J.J. Stickel, R.L. Powell, Fluid mechanics and rheology of dense suspensions, Annu. Rev. Fluid Mech., 37 (2005) 129-149.

[12] D. Chan, R. Powell, Rheology of suspensions of spherical particles in a Newtonian and a non-Newtonian fluid, Journal of non-Newtonian fluid mechanics, 15 (1984) 165-179. [13] R. Farris, Prediction of the viscosity of multimodal suspensions from unimodal viscosity data, Transactions of the Society of Rheology, 12 (1968) 281-301.

[14] I. Marti, O. Höfler, P. Fischer, E.J. Windhab, Rheology of concentrated suspensions containing mixtures of spheres and fibres, Rheologica acta, 44 (2005) 502-512.

[15] T.M. Bernaerts, A. Panozzo, V. Doumen, I. Foubert, L. Gheysen, K. Goiris, P. Moldenaers, M.E. Hendrickx, A.M. Van Loey, Microalgal biomass as a (multi) functional ingredient in food products: rheological properties of microalgal suspensions as affected by mechanical and thermal processing, Algal research, 25 (2017) 452-463.

[16] H. Fernandes, F. Lupi, M. Tomé, I. Sá-Correia, J. Novais, Rheological behaviour of the culture medium during growth of the microalga Botryococcus braunii, Bioresource technology, 38 (1991) 133-136.

[17] A. Wileman, A. Ozkan, H. Berberoglu, Rheological properties of algae slurries for minimizing harvesting energy requirements in biofuel production, Bioresource technology, 104 (2012) 432-439.

[18] B.H. Yap, G.J. Martin, P.J. Scales, Rheological manipulation of flocculated algal slurries to achieve high solids processing, Algal Research, 14 (2016) 1-8. 
[19] X. Zhang, Z. Jiang, L. Chen, A. Chou, H. Yan, Y.Y. Zuo, X. Zhang, Influence of cell properties on rheological characterization of microalgae suspensions, Bioresource technology, 139 (2013) 209-213.

[20] M.J. Scholz, T.L. Weiss, R.E. Jinkerson, J. Jing, R. Roth, U. Goodenough, M.C. Posewitz, H.G. Gerken, Ultrastructure and composition of the Nannochloropsis gaditana gaditana cell wall, Eukaryotic Cell, 13 (2014) 1450-1464.

[21] C. Van Eykelenburg, On the morphology and ultrastructure of the cell wall of Spirulina platensis platensis, Antonie van leeuwenhoek, 43 (1977) 89-99.

[22] G.S. Araujo, L.J. Matos, J.O. Fernandes, S.J. Cartaxo, L.R. Gonçalves, F.A.

Fernandes, W.R. Farias, Extraction of lipids from microalgae by ultrasound application:

Prospection of the optimal extraction method, Ultrasonics sonochemistry, 20 (2013) 95-98.

[23] J. Cheng, J. Sun, Y. Huang, J. Zhou, K. Cen, Fractal microstructure characterization of wet microalgal cells disrupted with ultrasonic cavitation for lipid extraction, Bioresource Technology, 170 (2014) 138-143.

[24] D.-Y. Kim, D. Vijayan, R. Praveenkumar, J.-I. Han, K. Lee, J.-Y. Park, W.-S. Chang, J.-S. Lee, Y.-K. Oh, Cell-wall disruption and lipid/astaxanthin extraction from microalgae: Chlorella and Haematococcus, Bioresource Technology, 199 (2016) 300-310.

[25] C. Safi, A.V. Ursu, C. Laroche, B. Zebib, O. Merah, P.-Y. Pontalier, C. Vaca-Garcia, Aqueous extraction of proteins from microalgae: Effect of different cell disruption methods, Algal Research, 3 (2014) 61-65.

[26] Y. Chisti, M. Moo-Young, Disruption of microbial cells for intracellular products, Enzyme and Microbial Technology, 8 (1986) 194-204.

[27] F. Adam, M. Abert-Vian, G. Peltier, F. Chemat, "Solvent-free" ultrasound-assisted extraction of lipids from fresh microalgae cells: A green, clean and scalable process, Bioresource Technology, 114 (2012) 457-465.

[28] U.D. Keris-Sen, U. Sen, G. Soydemir, M.D. Gurol, An investigation of ultrasound effect on microalgal cell integrity and lipid extraction efficiency, Bioresource Technology, 152 (2014) 407-413.

[29] M. Wang, W. Yuan, X. Jiang, Y. Jing, Z. Wang, Disruption of microalgal cells using high-frequency focused ultrasound, Bioresource Technology, 153 (2014) 315-321.

[30] M.J. Fabra, M. Martínez-Sanz, L.G. Gómez-Mascaraque, J.M. Coll-Marqués, J.C. Martínez, A. López-Rubio, Development and characterization of hybrid corn starchmicroalgae films: Effect of ultrasound pre-treatment on structural, barrier and mechanical performance, Algal Research, 28 (2017) 80-87.

[31] A. Martínez-Abad, N. Giummarella, M. Lawoko, F. Vilaplana, Differences in extractability under subcritical water reveal interconnected hemicellulose and lignin recalcitrance in birch hardwoods, Green Chemistry, 20 (2018) 2534-2546.

[32] J.F. Saeman, Kinetics of wood saccharification-hydrolysis of cellulose and decomposition of sugars in dilute acid at high temperature, Industrial \& Engineering Chemistry, 37 (1945) 43-52.

[33] S. Willför, A. Pranovich, T. Tamminen, J. Puls, C. Laine, A. Suurnäkki, B. Saake, K. Uotila, H. Simolin, J. Hemming, Carbohydrate analysis of plant materials with uronic acidcontaining polysaccharides-A comparison between different hydrolysis and subsequent chromatographic analytical techniques, Industrial Crops and Products, 29 (2009) 571-580. [34] P. G. Wiles, I. K. Gray, R. C. Kissling \& Collaborators, Routine analysis of proteins by Kjeldahl and Dumas methods: review and interlaboratory study using dairy products, Journal of AOAC International, 81(3) (1998) 620-632.

[35] C. Safi, M. Charton, O. Pignolet, F. Silvestre, C. Vaca-Garcia \& P. Y. Pontalier, Influence of microalgae cell wall characteristics on protein extractability and determination 
of nitrogen-to-protein conversion factors, Journal of applied phycology, 25(2) (2013) 523 529.

[36] C. V. G. López, M. D. C. C. García, F. G. A. Fernández, C. S. Bustos, Y. Chisti \& J. M. F. Sevilla, Protein measurements of microalgal and cyanobacterial biomass,

Bioresource technology, 101(19) (2010) 7587-7591.

[37] V.L. Singleton, R. Orthofer, R.M. Lamuela-Raventós, [14] Analysis of total phenols and other oxidation substrates and antioxidants by means of folin-ciocalteu reagent, Methods in enzymology, Elsevier1999, pp. 152-178.

[38] B. Ravindran, S.K. Gupta, W.-M. Cho, J.K. Kim, S.R. Lee, K.-H. Jeong, D.J. Lee, H.C. Choi, Microalgae potential and multiple roles - current progress and future prospectsan overview, Sustainability, 8 (2016) 1215.

[39] D.R. Vardon, B.K. Sharma, J. Scott, G. Yu, Z. Wang, L. Schideman, Y. Zhang, T.J. Strathmann, Chemical properties of biocrude oil from the hydrothermal liquefaction of Spirulina platensis algae, swine manure, and digested anaerobic sludge, Bioresource Technology, 102 (2011) 8295-8303.

[40] V.d.S. Braga, J.B. Moreira, J.A.V. Costa, M.G.d. Morais, Enhancement of the carbohydrate content in Spirulina platensis by applying CO2, thermoelectric fly ashes and reduced nitrogen supply, International Journal of Biological Macromolecules, 123 (2019) 1241-1247.

[41] E.J. Olguín, S. Galicia, O. Angulo-Guerrero, E. Hernández, The effect of low light flux and nitrogen deficiency on the chemical composition of Spirulina platensis sp.

(Arthrospira) grown on digested pig waste, Bioresource Technology, 77 (2001) 19-24. [42] J. Cheng, H. Lu, X. He, W. Yang, J. Zhou, K. Cen, Mutation of Spirulina platensis sp. by nuclear irradiation to improve growth rate under $15 \%$ carbon dioxide in flue gas, Bioresource Technology, 238 (2017) 650-656.

[43] J.F. Sánchez, J.M. Fernández, F.G. Acién, A. Rueda, J. Pérez-Parra, E. Molina, Influence of culture conditions on the productivity and lutein content of the new strain Scenedesmus almeriensis almeriensis, Process Biochemistry, 43 (2008) 398-405. [44] L. Sanchez-Silva, D. López-González, A.M. Garcia-Minguillan, J.L. Valverde, Pyrolysis, combustion and gasification characteristics of Nannochloropsis gaditana gaditana microalgae, Bioresource Technology, 130 (2013) 321-331.

[45] A.C. Guedes, H.M. Amaro, M.S. Gião, F.X. Malcata, Optimization of ABTS radical cation assay specifically for determination of antioxidant capacity of intracellular extracts of microalgae and cyanobacteria, Food Chemistry, 138 (2013) 638-643.

[46] S.P. Cuellar-Bermudez, I. Aguilar-Hernandez, D.L. Cardenas-Chavez, N. OrnelasSoto, M.A. Romero-Ogawa, R. Parra-Saldivar, Extraction and purification of high-value metabolites from microalgae: essential lipids, astaxanthin and phycobiliproteins, Microbial biotechnology, 8 (2015) 190-209.

[47] J.A. Gerde, M. Montalbo-Lomboy, L. Yao, D. Grewell, T. Wang, Evaluation of microalgae cell disruption by ultrasonic treatment, Bioresource Technology, 125 (2012) 175-181.

[48] L. Krienitz, M. Wirth, The high content of polyunsaturated fatty acids in Nannochloropsis gaditana limnetica (Eustigmatophyceae) and its implication for food web interactions, freshwater aquaculture and biotechnology, Limnologica, 36 (2006) 204-210. [49] B. Gilbert-López, J.A. Mendiola, L.A. van den Broek, B. Houweling-Tan, L. Sijtsma, A. Cifuentes, ,.. \& E. Ibáñez, Green compressed fluid technologies for downstream processing of Scenedesmus almeriensis obliquus in a biorefinery approach, Algal Research, 24, (2017) 111-121. 
[50] A. D. P. Sánchez-Camargo, N. Pleite, J. A. Mendiola, A. Cifuentes, M. Herrero, B. Gilbert-López \& E. Ibáñez, Development of green extraction processes for Nannochloropsis gaditana gaditana biomass valorization, Electrophoresis, 39(15) (2018) 1875-1883.

[51] M.C. Rocha de Souza, C.T. Marques, C.M. Guerra Dore, F.R. Ferreira da Silva, H.A. Oliveira Rocha, E.L. Leite, Antioxidant activities of sulfated polysaccharides from brown and red seaweeds, Journal of Applied Phycology, 19 (2007) 153-160.

[52] T. Wang, R. Jónsdóttir, H.G. Kristinsson, G.O. Hreggvidsson, J.Ó. Jónsson, G.

Thorkelsson, G. Ólafsdóttir, Enzyme-enhanced extraction of antioxidant ingredients from red algae Palmaria palmata, LWT - Food Science and Technology, 43 (2010) 1387-1393.

[53] Y.V. Yuan, N.D. Westcott, C. Hu, D.D. Kitts, Mycosporine-like amino acid composition of the edible red alga, Palmaria palmata (dulse) harvested from the west and east coasts of Grand Manan Island, New Brunswick, Food Chemistry, 112 (2009) 321-328. [54] E. Gómez-Ordóñez, P. Rupérez, FTIR-ATR spectroscopy as a tool for polysaccharide identification in edible brown and red seaweeds, Food hydrocolloids, 25 (2011) 15141520 .

[55] M.J. Scholz, T.L. Weiss, R.E. Jinkerson, J. Jing, R. Roth, U. Goodenough, M.C. Posewitz, H.G. Gerken, Ultrastructure and Composition of the $<$ span class="namedcontent genus-species" id="named-content-1" $>$ Nannochloropsis gaditana gaditana $</$ span $>$ Cell Wall, Eukaryotic Cell, 13 (2014) 1450-1464.

[56] Z. Du, Y. Li, X. Wang, Y. Wan, Q. Chen, C. Wang, X. Lin, Y. Liu, P. Chen, R. Ruan, Microwave-assisted pyrolysis of microalgae for biofuel production, Bioresource Technology, 102 (2011) 4890-4896.

[57] R. Mala, M. Sarojini, S. Saravanababu, G. Umadevi, Screening for antimicrobial activity of crude extracts of Spirulina platensis platensis, Journal of Cell and Tissue Research, 9 (2009) 1951.

[58] I. Benito-González, A. López-Rubio, A. Martínez-Abad, A.-R. Ballester, I. Falcó, L. González-Candelas, G. Sánchez, J. Lozano-Sánchez, I. Borrás-Linares, A. SeguraCarretero, In-Depth Characterization of Bioactive Extracts from Posidonia oceanica Waste Biomass, Marine drugs, 17 (2019) 409.

[59] M. Martínez-Sanz, L.G. Gómez-Mascaraque, A.R. Ballester, A. Martínez-Abad, A. Brodkorb, A. López-Rubio, Production of unpurified agar-based extracts from red seaweed Gelidium sesquipedale by means of simplified extraction protocols, Algal Research, 38 (2019) 101420.

[60] C. Safi, M. Charton, O. Pignolet, F. Silvestre, C. Vaca-Garcia, P.-Y. Pontalier, Influence of microalgae cell wall characteristics on protein extractability and determination of nitrogen-to-protein conversion factors, Journal of Applied Phycology, 25 (2013) 523529.

[61] H. Ma, H. Xiong, X. Zhu, C. Ji, J. Xue, R. Li, B. Ge, H. Cui, Polysaccharide from Spirulina platensis platensis ameliorates diphenoxylate-induced constipation symptoms in mice, International Journal of Biological Macromolecules, 133 (2019) 1090-1101. [62] Z.Y. Nie, J.L. Xia, J.M. Levert, Fractionation and characterization of polysaccharides from cyanobacterium Spirulina platensis (Arthrospira) maxima in nitrogen-limited batch culture, Journal of Central South University of Technology (English Edition), 9 (2002) 8186.

[63] K.M. Sekharam, L.V. Venkataraman, P.V. Salimath, Structural studies of a glucan isolated from blue-green alga Spirulina platensis platensis, Food Chemistry, 31 (1989) 8591. 
[64] Z.F. Wang, X.M. Peng, L.J. Huang, Z.Y. Peng, G.Y. Tian, Structure elucidation of glycan of a glycoconjugate SPPA-1 isolated from Spirulina platensis platensis, Yaoxue Xuebao, 36 (2001) 358-359.

[65] T. Kaji, M. Okabe, S. Shimada, C. Yamamoto, Y. Fujiwara, J.B. Lee, T. Hayashi, Sodium spirulan as a potent inhibitor of arterial smooth muscle cell proliferation in vitro, Life Sciences, 74 (2004) 2431-2439.

[66] L.V. Mikheiskaya, R.G. Ovodova, Y.S. Ovodov, Polysaccharides from Spirulina platensis platensis, Chemistry of Natural Compounds, 19 (1983) 127-131.

[67] R. Filali Mouhim, J.F. Cornet, T. Fontane, B. Fournet, G. Dubertret, Production, isolation and preliminary characterization of the exopolysaccharide of the cyanobacterium Spirulina platensis platensis, Biotechnology Letters, 15 (1993) 567-572.

[68] J.B. Lee, T. Hayashi, K. Hayashi, U. Sankawa, M. Maeda, T. Nemoto, H. Nakanishi, Further purification and structural analysis of calcium spirulan from Spirulina platensis platensis, Journal of Natural Products, 61 (1998) 1101-1104.

[69] A.P. Batista, L. Gouveia, N.M. Bandarra, J.M. Franco, A. Raymundo, Comparison of microalgal biomass profiles as novel functional ingredient for food products, Algal Research, 2 (2013) 164-173.

[70] F. Gelin, J.K. Volkman, C. Largeau, S. Derenne, J.S. Sinninghe Damsté, J.W. De Leeuw, Distribution of aliphatic, nonhydrolyzable biopolymers in marine microalgae, Organic Geochemistry, 30 (1999) 147-159.

[71] T.M.M. Bernaerts, L. Gheysen, C. Kyomugasho, Z. Jamsazzadeh Kermani, S. Vandionant, I. Foubert, M.E. Hendrickx, A.M. Van Loey, Comparison of microalgal biomasses as functional food ingredients: Focus on the composition of cell wall related polysaccharides, Algal Research, 32 (2018) 150-161.

[72] M.R. Brown, The amino-acid and sugar composition of 16 species of microalgae used in mariculture, Journal of Experimental Marine Biology and Ecology, 145 (1991) 79-99. [73] E. Teuling, J.W. Schrama, H. Gruppen, P.A. Wierenga, Effect of cell wall characteristics on algae nutrient digestibility in Nile tilapia (Oreochromis niloticus) and African catfish (Clarus gariepinus), Aquaculture, 479 (2017) 490-500.

[74] H. Takeda, Cell wall sugars of some Scenedesmus almeriensis species, Phytochemistry, 42 (1996) 673-675.

[75] J. Zhang, L. Liu, Y. Ren, F. Chen, Characterization of exopolysaccharides produced by microalgae with antitumor activity on human colon cancer cells, International Journal of Biological Macromolecules, 128 (2019) 761-767.

[76] S.L. Guo, X.Q. Zhao, C. Wan, Z.Y. Huang, Y.L. Yang, M. Asraful Alam, S.H. Ho, F.W. Bai, J.S. Chang, Characterization of flocculating agent from the self-flocculating microalga Scenedesmus almeriensis obliquus AS-6-1 for efficient biomass harvest, Bioresource Technology, 145 (2013) 285-289.

[77] M.G. de Morais, C. Stillings, R. Dersch, M. Rudisile, P. Pranke, J.A.V. Costa, J. Wendorff, Preparation of nanofibers containing the microalga Spirulina platensis (Arthrospira), Bioresource Technology, 101 (2010) 2872-2876.

[78] M.-C. Lee, Y.-C. Chen, T.-C. Peng, Two-stage culture method for optimized polysaccharide production in Spirulina platensis platensis, Journal of the Science of Food and Agriculture, 92 (2012) 1562-1569.

[79] A. Shrivastav, S.K. Mishra, S. Mishra, Polyhydroxyalkanoate (PHA) synthesis by Spirulina platensis subsalsa from Gujarat coast of India, International Journal of Biological Macromolecules, 46 (2010) 255-260. 
[80] L. Krienitz, D. Hepperle, H.-B. Stich, W. Weiler, Nannochloropsis gaditana limnetica (Eustigmatophyceae), a new species of picoplankton from freshwater, Phycologia, 39 (2000) 219-227.

[81] S. Suda, M. Atsumi, H. Miyashita, Taxonomic characterization of a marine Nannochloropsis gaditana species, N. oceanica sp. nov. (Eustigmatophyceae), Phycologia, 41 (2002) 273-279.

[82] M.-C. Chan, S.-H. Ho, D.-J. Lee, C.-Y. Chen, C.-C. Huang, J.-S. Chang, Characterization, extraction and purification of lutein produced by an indigenous microalga Scenedesmus almeriensis obliquus CNW-N, Biochemical Engineering Journal, 78 (2013) 24-31.

[83] P. Přibyl, V. Cepák, P. Kaštánek, V. Zachleder, Elevated production of carotenoids by a new isolate of Scenedesmus almeriensis sp, Algal Research, 11 (2015) 22-27.

[84] M.K. Danquah, B. Gladman, N. Moheimani, G.M. Forde, Microalgal growth characteristics and subsequent influence on dewatering efficiency, Chemical Engineering Journal, 151 (2009) 73-78.

[85] S. Salim, L. Gilissen, A. Rinzema, M. Vermuë, R. Wijffels, Modeling microalgal flocculation and sedimentation, Bioresource technology, 144 (2013) 602-607.

[86] S. Salim, N. Kosterink, N.T. Wacka, M. Vermuë, R. Wijffels, Mechanism behind autoflocculation of unicellular green microalgae Ettlia texensis, Journal of biotechnology, 174 (2014) 34-38.

[87] N. Schneider, M. Gerber, Correlation between viscosity, temperature and total solid content of algal biomass, Bioresource technology, 170 (2014) 293-302.

[88] P. Lopez-Sanchez, J. Nijsse, H.C. Blonk, L. Bialek, S. Schumm, M. Langton, Effect of mechanical and thermal treatments on the microstructure and rheological properties of carrot, broccoli and tomato dispersions, Journal of the Science of Food and Agriculture, 91 (2011) 207-217.

[89] C. Valencia, M. Sanchez, A. Ciruelos, A. Latorre, J. Madiedo, C. Gallegos, Nonlinear viscoelasticity modeling of tomato paste products, Food Research International, 36 (2003) 911-919.

[90] B. Yoo, M. Rao, Effect of unimodal particle size and pulp content on rheological properties of tomato puree, Journal of Texture Studies, 25 (1994) 421-436.

[91] I.D. Evans, A. Lips, Concentration dependence of the linear elastic behaviour of model microgel dispersions, Journal of the Chemical Society, Faraday Transactions, 86 (1990) 3413-3417.

[92] A.H. Clark, S.B. Ross-Murphy, Structural and mechanical properties of biopolymer gels, Biopolymers, Springer1987, pp. 57-192. 